\title{
Synthesis and Antitubercular Activity of New Benzo[b]thiophenes
}

\author{
Pravin S. Mahajan, ${ }^{\dagger}$ Mukesh D. Nikam, ${ }^{\dagger}$ Laxman U. Nawale, ${ }^{\ddagger}$ Vijay M. Khedkar, ${ }^{\ddagger}$ Dhiman Sarkar, ${ }^{\ddagger}$ \\ and Charansingh H. Gill*, ${ }^{\dagger}$
}

${ }^{\dagger}$ Department of Chemistry, Dr. Babasaheb Ambedkar Marathwada University, Aurangabad, 431004 Maharashtra, India

${ }^{\ddagger}$ Combi-Chem Resource Centre, CSIR-National Chemical Laboratory, Pune, 411008 Maharashtra, India

\section{Supporting Information}

\begin{abstract}
In vitro and ex vivo efficacies of four series of benzo[b]thiophene-2carboxylic acid derivatives were studied against Mycobacterium tuberculosis H37Ra (MTB). Benzo[b]thiophenes were also tested in vitro against multidrug resistant Mycobacterium tuberculosis H37Ra (MDR-MTB), and $7 \mathbf{b}$ was found to be highly active against A- and DMDR-MTB/MTB (MIC ranges 2.73-22.86 $\mu \mathrm{g} / \mathrm{mL}$ ). The activity of all benzo[b]thiophenes against $M$. bovis BCG (BCG) was also assessed grown under aerobic and under conditions of oxygen depletion. Compounds $8 \mathrm{c}$ and $8 \mathrm{~g}$ showed significant activity with MICs of 0.60 and $0.61 \mu \mathrm{g} / \mathrm{mL}$ against dormant BCG. The low cytotoxicity and high

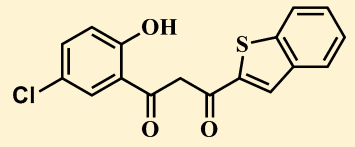

Ex vivo H37Ra (MIC) MDR H37Ra (MIC) Active: $2.83 \quad$ Active: $\mathbf{5 . 3}$ Dormant: 0.91 Dormant: 2.73 selectivity index data against human cancer cell lines, HeLa, Panc-1, and THP-1 indicate the potential importance of the development of benzo[b]thiophene-based 1,3-diketones and flavones as lead candidates to treat mycobacterial infections. Molecular docking studies into the active site of DprE1 (Decaprenylphosphoryl- $\beta$-D-ribose- $2^{\prime}$-epimerase) enzyme revealed a similar binding mode to native ligand in the crystal structure thereby helping to understand the ligand-protein interactions and establish a structural basis for inhibition of MTB. In summary, its good activity in in vitro and ex vivo model, as well as its activity against multidrug-resistant $M$. tuberculosis $\mathrm{H} 37 \mathrm{Ra}$ in a potentially latent state, makes $7 \mathbf{b}$ an attractive drug candidate for the therapy of tuberculosis.
\end{abstract}

KEYWORDS: Benzo[b]thiophene, MDR-MTB, M. Bovis BCG, cytotoxicity, molecular docking

A mong infectious widespread diseases, tuberculosis (TB) remains an active and major health problem worldwide. TB is the deadliest communicable disease, caused by the global emergence of multidrug resistant (MDR) and extensively drug resistant (XDR) strains of TB along with acquired, primary, and cross resistance mycobacterium TB (MTB) strains. Despite the availability of first line and second line drugs regimen to treat the disease, still unacceptably $\mathrm{TB}$ continues to have high mortality and a global health threat. Resistance to first line antiTB drugs has been linked to spontaneous mutations in many genes. ${ }^{1}$ The probability of resistance arising when rifampicin and isoniazid are used in combination is only one in $10^{14}$, sufficiently low to prevent resistance for either drug. ${ }^{2}$ As per $\mathrm{WHO}$, the direct observed therapy strategy (DOTS) is the most effective means to prevent the emergence of drug resistance. ${ }^{3}$ As for those with HIV, several other inter-related factors like poverty, mobility of people from the countries where $\mathrm{TB}$ is prevalent, the long and complex $\mathrm{TB}$ regimen, and poor management of $\mathrm{TB}$ control programs ${ }^{4}$ pose the resurgence of TB.

Mycobacterium bovis Bacillus Calmette Guerin (BCG), an attenuated strain closely related to $M T B,{ }^{5}$ infections in humans have been reported from many centuries ago. $M$. bovis infections have re-emerged and are causing TB in humans, due to mutations during the long in vitro propagation of this strain and, in particular, those who are HIV-positive. Owing to the appearance of drug resistance surveillance, the significant side effects and drug interactions of present agents, there is still an urgent need for the development of new ideal anti-TB agents with low toxicity and those that are active to treat against MDR and XDR bacteria and latent diseases.

Based on these facts, efforts have been continued to discover new and effective chemotherapeutic agents for the tuberculosis treatment. We recently reported the antitubercular activity of several new molecules with good minimum inhibitory concentrations (MICs), ${ }^{6-11}$ which promoted us to synthesize new compounds.

Benzo $[b]$ thiophene moiety is a drug-like scaffold known to possess potential medicinal value in FDA approved drugs such as raloxifene, sertaconazole, zileuton, and benocyclidine. Therefore, in continuation of our program on the discovery of antitubercular compounds, various 1,3-diketones, flavones, pyrazoles, and carboxamides were synthesized from benzo $[b]$ thiophene carboxylic acid and demonstrated inhibitory activity against MTB H37Ra and M. bovis BCG. The cytotoxicity of compounds has been also tested.

In an effort to elucidate the possible mechanism by which the title compounds can induce antitubercular activity, molecular docking studies were performed to visualize the binding mode of the drug candidate at the molecular level. In the absence of resources to perform the target-based assays experimentally, the in silico approach of molecular docking has proved to be a very

Received: February 20, 2016

Accepted: June 28, 2016

Published: June 28, 2016 
important tool for identifying the targets for different ligands and their associated thermodynamic intermolecular interactions with the target enzyme governing the inhibition of the pathogen. Molecular docking studies into the active site of DprE1 (decaprenylphosphoryl- $\beta$-D-ribose- 2 '-epimerase) enzyme revealed a similar binding mode to native ligand in the crystal structure thereby helping to understand the ligandprotein interactions and establish a structural basis for inhibition of MTB.

The synthetic sequences of benzo[ $[b]$ thiophene derivatives are illustrated in Scheme 1. Commercially available 2-

Scheme 1. Synthesis of Benzo[b]$\left[\right.$ thiophene Derivatives $^{a}$

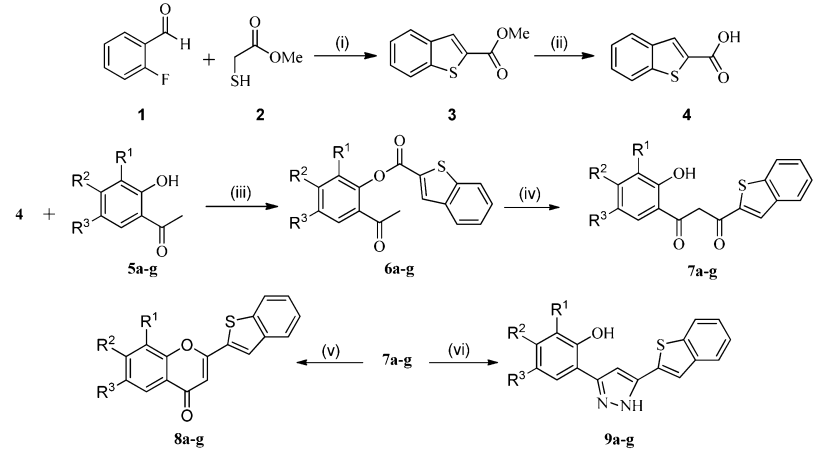

$7 a, 8 a, 9 a ; R_{1}=-H, R_{2}=-H, R_{3}=-B r ; 7 b, 8 b, 9 b ; R_{1}=-H, R_{2}=-H, R_{3}=-C l ; 7 c, 8 c, 9 c ; R_{1}=-H$ $\mathrm{R}_{2}=-\mathrm{H}, \mathrm{R}_{3}=-\mathrm{CH}_{3} ; 7 \mathrm{~d}, 8 \mathrm{~d}, 9 \mathrm{~d} ; \mathrm{R}_{1}=-\mathrm{H}, \mathrm{R}_{2}=-\mathrm{H}, \mathrm{R}_{3}=-\mathrm{H} ; 7 \mathrm{e}, 8 \mathrm{e}, 9 \mathrm{e} ; \mathrm{R}_{1}=-\mathrm{Cl}, \mathrm{R}_{2}=-\mathrm{H}, \mathrm{R}_{3}=-\mathrm{Cl}$; 7f, 8f, 9f; $R_{1}=-H, R_{2}=-C_{3}, R_{3}=-H ; 7 g, 8 g, 9 g ; R_{1}=-H, R_{2}=-C_{3}, R_{3}=-C l$

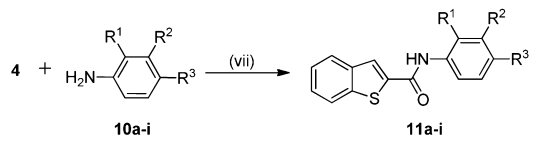

11a; $R_{1}=-H, R_{2}=-H, R_{3}=-B r ; 11 b ; R_{1}=-H, R_{2}=-H, R_{3}=-H ; 11 c ; R_{1}=-F, R_{2}=-H, R_{3}=-H$ 11d; $R_{1}=-H, R_{2}=-H, R_{3}=-F ; 11 e ; R_{1}=-F, R_{2}=-H, R_{3}=-F ; 11 f ; R_{1}=-H, R_{2}=-B r, R_{3}=-H$; 11g; $R_{1}=-H, R_{2}=-H, R_{3}=-C l ; 11 h ; R_{1}=-H, R_{2}=-C l, R_{3}=-H ; 11 ; ; R_{1}=-C l, R_{2}=-H, R_{3}=-H$

${ }^{a}$ Reagents and conditions: (i) $\mathrm{K}_{2} \mathrm{CO}_{3}$, DMF; (ii) $\mathrm{LiOH}, \mathrm{THF} / \mathrm{H}_{2} \mathrm{O}$; (iii) pyridine, $\mathrm{POCl}_{3}, \mathrm{RT}$; (iv) $\mathrm{KOH}$, pyridine. (v) PEG-400, cat. $\mathrm{H}_{2} \mathrm{SO}_{4}$; (vi) $\mathrm{NH}_{2} \mathrm{NH}_{2} \cdot \mathrm{H}_{2} \mathrm{O}$; (vii) EDC.HCl, HOBt, DMF.

fluorobenzaldehyde 1 was reacted with methyl 2-mercaptoacetate $\mathbf{2}$ in $\mathrm{N}, \mathrm{N}$-dimethylformamide (DMF) under basic $\left(\mathrm{K}_{2} \mathrm{CO}_{3}\right)$ conditions followed by base $(\mathrm{LiOH})$ hydrolysis affording benzo $[b]$ thiophene-2-carboxylic acid 4 . Further, the reaction between compound 4 and appropriate $o$-hydroxy acetophenones $\mathbf{5 a}-\mathbf{g}$ in pyridine and $\mathrm{POCl}_{3}$ provided intermediate esters $\mathbf{6} \mathbf{a}-\mathbf{g}$. In the next step, these intermediate undergoes
Baker-Venkataraman rearrangement (BVR) under ultrasonication, affording 1-(benzo[b]thiophen-2-yl)-3-(2hydroxyphenyl)propane-1,3-diones $7 \mathbf{a}-\mathrm{g}$.

The intramolecular cyclization of 1,3-diketones $7 \mathbf{a}-\mathbf{g}$ yielded novel 2-(benzo[b]thiophen-2-yl)-4H-chromen-4-ones $8 \mathbf{a}-\mathbf{g}$ in good yields. The formation of the chromen-4-ones was accomplished through a different protocol, PEG-400 as a green solvent with a nonconventional approach, and ultrasound irradiation was successfully utilized. Moreover, 2-(5-(benzo[b]thiophen-2-yl)-1H-pyrazol-3-yl)phenols $9 \mathbf{a}-\mathbf{g}$ synthesis proceeds via a condensation reaction between substituted 1(benzo[b]thiophen-2-yl)-3-(2-hydroxyphenyl)propane-1,3-diones $7 \mathbf{a}-\mathbf{g}$ and hydrazine hydrate in ethanol under ultrasound irradiation. Further, the condensation reaction between compound 4 and anilines $10 \mathrm{a}-\mathbf{i}$ using $\mathrm{EDC} \cdot \mathrm{HCl}$ and $\mathrm{HOBt}$ as coupling reagents under ultrasound irradiation within $1-2 \mathrm{~h}$ afforded carboxamides $11 \mathbf{a}-\mathbf{i}$. The structures of the compounds were chemically characterized by thin layer chromatography (TLC), spectroscopic data, and elemental analyses.

All 31 synthesized compounds were tested for their in vitro anti-TB activity., 92 The primary screen results showed that four compounds $7 \mathbf{a}, 7 \mathbf{b}, 7 \mathrm{~d}$, and $7 \mathbf{f}$ in particular exhibit $>92 \%$ inhibitory activity against MTB H37Ra and nine compounds $\mathbf{7 a}-\mathbf{d}, \mathbf{7 f}, \mathbf{7 g}$, and $\mathbf{9 b}-\mathbf{d}$ exhibit $>97 \%$ against $M$. bovis BCG strain (Supporting Information). Compounds $\mathbf{7 a}-\mathbf{f}, \mathbf{8 c}$ and $\mathbf{8 g}$ have been selected for further evaluation to dose response by both the $\mathrm{IC}_{50}$ (Supporting Information) and $\mathrm{MIC}_{90}$ (minimum concentration bringing $90 \%$ inhibition) values presented in Table 1.

The 1,3-diketone $\mathbf{7} \mathbf{d}$ with no substitution appears to provide strong activity against dormant MTB H37Ra (MIC $=2.05 \mu \mathrm{g}$ / $\mathrm{mL}$ ). Compounds $7 \mathbf{a}$ and $7 \mathbf{b}$ having bromo substituent showed good activity against active as well as dormant MTB H37Ra with MIC value of 2.87 and $2.63 \mu \mathrm{g} / \mathrm{mL}$, respectively. However, it was observed that the compounds are more susceptible to $M$. bovis BCG than MTB H37Ra, providing significantly enhanced biological activities against these mycobacteria. Compounds $7 \mathbf{g}$, $\mathbf{8 g}, \mathbf{8 c}, \mathbf{7 f}, \mathbf{7 d}$, and $7 \mathbf{a}$ exhibited notable inhibitory activity, having MIC values in the $0.56-1.90 \mu \mathrm{g} / \mathrm{mL}$ range against active M. bovis BCG, and compounds $8 \mathrm{~g}, 8 \mathrm{c}, 7 \mathrm{~g}, 7 \mathrm{a}, 7 \mathrm{~d}, 7 \mathrm{~b}$ and $7 \mathrm{c}$ with $0.60-1.37 \mu \mathrm{g} / \mathrm{mL}$ range showed excellent activity against dormant $M$. bovis BCG. We observed that compounds with methyl (7c, $7 \mathbf{f}$ and $\mathbf{8 c})$ or both methyl and chloro groups $(7 \mathrm{~g}$ and $\mathbf{8 g}$ ) are more effective than other derivatives. Importantly, the flavone $8 \mathrm{~g}$ exhibited superior activity against both active

Table 1. Antitubercular Activity of Compounds $7 \mathrm{a}-\mathrm{b}, 7 \mathrm{~d}, 7 \mathrm{f}, 8 \mathrm{c}$, and $8 \mathrm{~g}$

\begin{tabular}{|c|c|c|c|c|c|c|c|c|c|}
\hline \multirow[b]{4}{*}{ compd } & \multicolumn{8}{|c|}{$\mathrm{MIC}_{90}$} & \multirow[b]{4}{*}{$\operatorname{cLog} \mathrm{P}^{a}$} \\
\hline & \multirow{2}{*}{\multicolumn{2}{|c|}{$\frac{\text { ex vivo }}{\text { MTB H37Ra }}$}} & \multicolumn{6}{|c|}{ in vitro } & \\
\hline & & & \multicolumn{2}{|c|}{ drug resistant $\mathrm{H} 37 \mathrm{Ra}$} & \multicolumn{2}{|c|}{ MTB H37Ra } & \multicolumn{2}{|c|}{ M. bovis $\mathrm{BCG}$} & \\
\hline & active & dormant & active & dormant & active & dormant & active & dormant & \\
\hline $7 a$ & 4.94 & 3.91 & 8.04 & 7.11 & 2.87 & 2.63 & 1.16 & 1.77 & 5.12 \\
\hline $7 \mathbf{b}$ & 2.83 & 0.91 & 5.3 & 2.73 & 3.29 & 2.79 & 2.22 & 2.7 & 4.97 \\
\hline $7 d$ & 2.96 & 1.82 & 12.41 & 2.87 & 25.17 & 2.05 & 2.34 & 1.36 & 4.13 \\
\hline $7 \mathrm{f}$ & 25.84 & 2.61 & 8.97 & 9.42 & 5.45 & 4.41 & 1.68 & 1.61 & 4.62 \\
\hline $8 \mathrm{c}$ & 8.39 & 2.76 & 22.86 & 7.22 & 28.87 & 29.98 & 0.62 & 0.61 & 5.23 \\
\hline $8 g$ & 7.67 & 2.18 & 9.58 & 9.1 & 25.36 & 24.34 & 0.56 & 0.60 & 5.94 \\
\hline $\mathrm{RP}$ & 0.5 & 0.8 & $>10$ & $>10$ & 0.048 & 0.043 & 0.004 & 0.0042 & \\
\hline INH & 0.05 & 0.075 & $>10$ & $>10$ & 0.074 & 0.075 & 0.075 & 0.0078 & \\
\hline
\end{tabular}

${ }^{a}$ LogP calculated using ChemDraw Ultra 12.0 software by Cambridge Soft. 
Table 2. Cytotoxicity of Compounds $7 \mathrm{a}-\mathrm{g}, 8 \mathrm{c}$, and $8 \mathrm{~g}$

\begin{tabular}{|c|c|c|c|c|c|c|}
\hline \multirow[b]{2}{*}{ compd } & \multicolumn{2}{|c|}{ HeLa } & \multicolumn{2}{|c|}{ Panc-1 } & \multicolumn{2}{|c|}{ THP-1 } \\
\hline & $\mathrm{GI}_{50}$ & $\mathrm{GI}_{90}$ & $\mathrm{GI}_{50}$ & $\mathrm{GI}_{90}$ & $\mathrm{GI}_{50}$ & $\mathrm{GI}_{90}$ \\
\hline $7 a$ & 6.75 & 20.28 & 18.33 & $>30$ & $>100$ & $>100$ \\
\hline $7 \mathbf{b}$ & 4.42 & 8.24 & 8.44 & 26.03 & 7.48 & $>30$ \\
\hline $7 \mathrm{c}$ & 7.12 & $>30$ & 15.83 & $>30$ & $>100$ & $>100$ \\
\hline $7 d$ & 7.86 & $>30$ & 7.77 & $>30$ & $>100$ & $>100$ \\
\hline $7 e$ & $>100$ & $>100$ & 26.22 & $>30$ & $>100$ & $>100$ \\
\hline $7 \mathrm{f}$ & 23.11 & $>30$ & 9.24 & $>30$ & $>100$ & $>100$ \\
\hline $7 \mathrm{~g}$ & $>100$ & $>100$ & 20.36 & $>30$ & $>100$ & $>100$ \\
\hline $8 c$ & 15.55 & 27.8 & 12.87 & 29.75 & $>100$ & $>100$ \\
\hline $8 \mathrm{~g}$ & 21.22 & $>30$ & $>100$ & $>100$ & $>100$ & $>100$ \\
\hline paclitaxel $^{a}$ & 0.004 & 0.075 & 0.127 & 5.715 & 0.133 & 5.81 \\
\hline
\end{tabular}

$(\mathrm{MIC}=0.56 \mu \mathrm{g} / \mathrm{mL})$ and dormant $(\mathrm{MIC}=0.60 \mu \mathrm{g} / \mathrm{mL}) M$. bovis BCG. In other derivatives, the flavone $8 \mathrm{c}$ with MIC value of 0.62 and $0.61 \mu \mathrm{g} / \mathrm{mL}$ against active and dormant $M$. bovis BCG, respectively, and 1,3-diketone $7 \mathrm{~g}$ with MIC value of 0.71 and $0.90 \mu \mathrm{g} / \mathrm{mL}$ against active and dormant $M$. bovis BCG, respectively, also exhibited excellent anti-TB activity. Compounds with hydrogen $(7 \mathbf{d})$, one chloro group (7b), and two chloro groups (7e) showed significant reduction of $M$. bovis BCG growth. Replacement of the chloro group by bromo group (7a) offers an advantage in the inhibition of $M$. bovis BCG growth, resulting in a dramatic enhancement of activity.

The activity of benzo[b]thiophene-2-carboxylic acid derivatives against multidrug-resistant $\mathrm{H} 37 \mathrm{Ra}$ was determined by a "microdilution" 96-well plate assay. ${ }^{13,14}$ On every microtiter plate containing one MDR MTB H37Ra strain, a dilution series of RIF and INH was included as positive control compounds. The results for all the compounds $7 \mathbf{a}-\mathbf{f}, 8 \mathbf{c}$, and $8 \mathrm{~g}$ at concentrations of $30-0.001 \mu \mathrm{g} / \mathrm{mL}$ (one-third dilutions) were scored by using an established XTT Reduction Menadione assay (XRMA), ${ }^{12}$ and the results are presented in Table 1 . The results were also cross checked by taking a final spectrophotometric reading of the microtiter plates at $600 \mathrm{~nm}$. The most active compounds $\mathbf{7 a}-\mathbf{f}, \mathbf{8 c}$, and $\mathbf{8 g}$ were highly active against multidrug-resistant $M$. tuberculosis H37Ra (MICs range, 2.73 to $22.86 \mu \mathrm{g} / \mathrm{mL}$ against active and dormant stages). Compound $7 \mathbf{b}$ having one bromo and one chloro substituent was highly active against multidrug-resistant MTB H37Ra ( $\mathrm{MIC}=2.73$ $\mu \mathrm{g} / \mathrm{mL}$ against dormant stage). In the same experiment, the activity of the compounds was compared to those of clinically available compounds RIF and INH and were found to be slightly better than that of RIF and INH.

These synthetic compounds $7 \mathbf{a}-\mathbf{f}, \mathbf{8 c}$, and $\mathbf{8 g}$ were further tested to determine their MIC against mycobacteria within THP-1 host macrophages (Table 1). Ex vivo studies against $M T B$ revealed the strong anti-TB activity of benzo[b]thiophene-2-carboxylic acid derivatives $(\mathbf{7 a}-\mathbf{f}, \mathbf{8 c}$, and $8 \mathrm{~g}$ ).

Among derivatives, $7 \mathbf{b}$ was found to be highly effective and inhibited both active and dormant mycobacteria with MIC ranging from 0.91 to $2.83 \mu \mathrm{g} / \mathrm{mL}$, corroborating its antimicrobial nature. However, the activity is not as profound as that of RIF and INH. The pattern was similar in ex vivo THP-1 infection model assay with MDR MTB H37Ra (in vitro) with compounds having the highest efficiency to inhibit MTB.

The cytotoxicity is important to find out potent antibiotics and to get insight into potential toxicity of identified inhibitor molecules. The cytotoxicity of most potent anti-TB agents 7a$\mathrm{g}, \mathbf{8 c}$, and $8 \mathrm{~g}$ was further assessed against a panel of three human cancer cell lines HeLa (human epithelial cervical cancer), Panc-1 (pancreas carcinoma), and THP-1 (acute monocytic leukemia) using modified MTT cell viability assay. $^{15-17}$ The cytotoxic effect of these compounds was checked to determine the growth inhibition (GI), $\mathrm{GI}_{50}$ (Supporting Information) and $\mathrm{GI}_{90}$, and paclitaxel was used as positive control (Table 2).

Except $\mathbf{7 a}, \mathbf{7 b}$, and $\mathbf{8 c}$, all compounds showed $\mathrm{GI}_{90}$ values $>30 \mu \mathrm{g} / \mathrm{mL}$ in HeLa cell line. In the case of Panc-1 cell line, except $7 \mathbf{b}$ and $\mathbf{8 c}$, all other compounds showed $\mathrm{GI}_{90}$ values $>30$ $\mu \mathrm{g} / \mathrm{mL}$. Notably, all compounds showed cytotoxic $\mathrm{GI}_{90}>30$ $\mu \mathrm{g} / \mathrm{mL}$ on THP-1 cell line. Overall, all the tested compounds had low cytotoxic effect on these three human cell lines. The ratios between $\mathrm{IC}_{50}$ for human cancer cell lines (cytotoxicity) and MIC (antimycobacterial activity) in vitro against both active and dormant $M T B$ H37Ra and $M$. bovis $\mathrm{BCG}^{18,19}$ enabled the determination of selectivity index (SI) (Supporting Information). According to drug susceptibility study of TB, compounds that exhibited SI values $>10$ in all three cell lines were considered nontoxic. ${ }^{20}$ For simultaneous detection of active and dormant stage inhibitors against tubercular bacilli, XRMA assay protocol was used, which follows a similar principle of hypoxia model of dormancy. ${ }^{21}$

When comparing the toxicity exhibited by these potent antitubercular 1,3-diketones and flavones, one compound $\mathbf{8 g}$ exhibited comparatively higher selectivity index $($ SI > 30) at active and dormant state of THP-1 cell line of both MTB H37Ra and M. bovis BCG. Compounds $7 \mathbf{f}(>13)$ and $\mathbf{8 g}(>35)$ against both active and dormant HeLa cell line of $M$. bovis BCG possesses superior selectivity index. Importantly, 1,3-diketone derivative $8 \mathbf{c}$ possessed a more favorable selectivity index (SI > 20) against all active and dormant three cell lines of $M$. bovis BCG. In addition, compound $7 \mathbf{a}(>10)$ against active and dormant Panc-1 cell line, compounds $7 \mathrm{c}$ and $7 \mathrm{e}(>10)$ against dormant Panc-1 cell line, and compounds $7 \mathrm{~g}$ and $8 \mathrm{c}(>22)$ against active and dormant state of THP-1 cell line exhibited better selectivity index for $M$. bovis BCG. These results demonstrated that compounds $\mathbf{8 c}$ and $\mathbf{8 g}$ have been found to have potential against MTB H37Ra and M. bovis BCG.

Mycobacteria can induce ROS (reactive oxygen species) production by activating phagocytes. ${ }^{22}$ Although these are an important part of the host defense against mycobacteria, enhanced ROS generation may promote tissue injury and inflammation, which may further contribute to immunosuppression, ${ }^{23}$ particularly in HIV infected patients. ${ }^{24}$ Therefore, the antioxidant activity of the antitubercular compounds was assessed by DPPH (1,1-diphenyl-2-picryl-hydrazil) radical 
scavenging method ${ }^{25,26}$ (Supporting Information). The interaction of all tested compounds with the stable free radical $\mathrm{DPPH}$ indicates their radical scavenging activity by $\mathrm{EC}_{50}$ (effective concentration). These results indicate that the antioxidant activity of the 1,3-diketone and flavone derivatives could not simply be attributed to their antitubercular activity. The 1,3-diketone $7 f\left(\mathrm{EC}_{50}=20.00 \mu \mathrm{g} / \mathrm{mL}\right)$ was the best synthetic antioxidant as compared to standard antioxidant drug BHT.

Promising antitubercular activities demonstrated by benzo[b]thiophene-2-carboxylic acid derivatives motivated us to perform molecular docking studies to identify a potential target for them and thereby gaining an insight into the key molecular mechanisms in exerting inhibitory activity against MTB.

After scanning through the crystal structures available for mycobacterium targets in the Protein Data Bank (PDB), we obtained a fairly good agreement between experimental antitubercular data and the docking results against DprE1 enzyme (Figure 1). It is a key enzyme involved in the

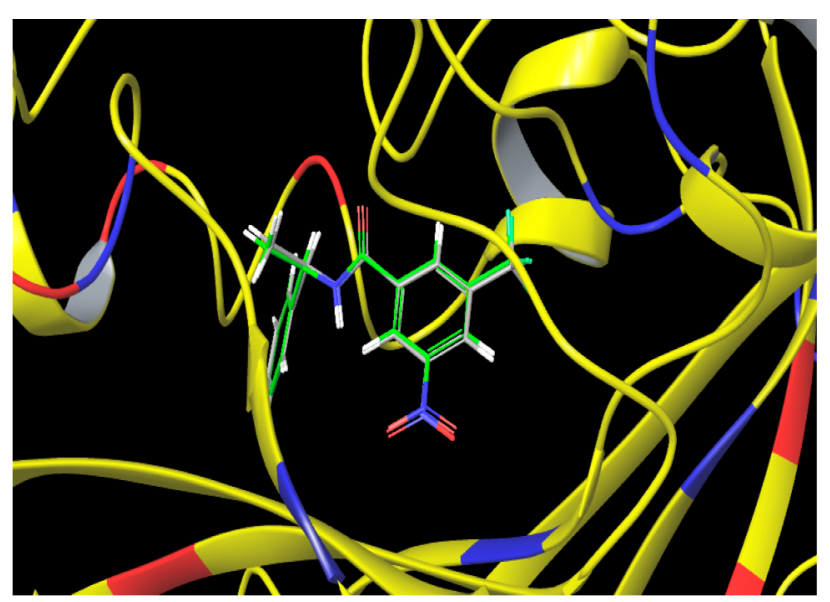

Figure 1. Overlay of the crystallographically observed binding mode of the native ligand on its best docked conformation.

biosynthesis of decaprenylphosphoryl-D-arabinose (DPA), which is the only known donor of D-arabinofuranosyl residues for the synthesis of arabinogalactan, a basic precursor for the mycobacterial cell wall core. ${ }^{27,28}$ Therefore, DprE1 is also essential for the cell growth and survival making it a potential target for antimycobacterial drug design strategy. ${ }^{29-32}$ Molecular docking study was performed using the standard protocol implemented in the GLIDE (Grid-based Ligand Docking with Energetics) module of the Schrodinger Molecular modeling package (Schrodinger, LLC, New York, NY, 2015). ${ }^{33,34}$

In order to rationalize the observed antitubercular results and to get more insight into the inhibition pattern, interactions of benzo[b]thiophene-2-carboxylic acid derivatives with the binding pocket of mycobacterial (DprE1) were analyzed and depicted using molecular docking studies. ${ }^{28}$ Visual inspection of the minimum energy docked poses revealed that these derivatives snuggly fit into the binding pocket, making close contacts with the surrounding residues.

Their docking score varied from -9.198 for the most active analogue $7 \mathbf{a}$ to -6.995 for the least active $7 \mathrm{e}$, while the docking score for the native ligand was found to be -7.953 . This trend of docking scores corroborated well with the observed antitubercular activity where the active compounds showed higher scores, while those with relatively low inhibition were also predicted to have a lower docking score. Quantitative measures of the docking scores along with binding energy and noncovalent interactions observed for these derivatives are summarized in the Table S4 (Supporting Information). A detailed per-residue interaction analysis between the protein and the most active analogue $7 \mathbf{a}$ only is elucidated in the next section for the sake of brevity through which we can speculate regarding the binding patterns in the cavity.

The binding mode of $7 \mathbf{a}$ is presented in Figure 2. Though it showed multiple interactions with the residues in the active site,

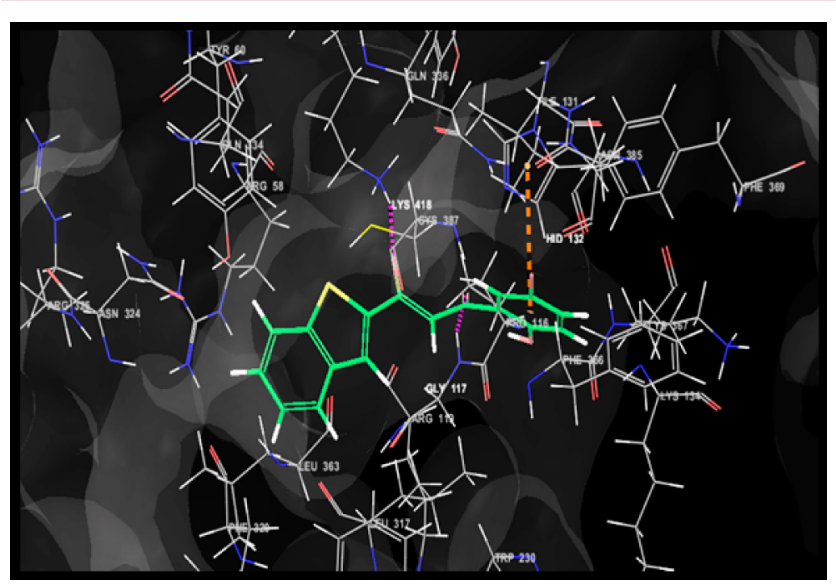

Figure 2. Binding mode of the most active compound $7 \mathbf{a}$ into active site of DprE1.

however, for visibility and clarity only selected interacting residue are exhibited. Analysis of the docked complex showed very strong binding affinity $(-50.095 \mathrm{kcal} / \mathrm{mol})$ with the receptor wherein the contribution of the van der Waals interactions $(-45.951 \mathrm{kcal} / \mathrm{mol})$ was found to be more than the Coulombic interactions $(-4.144 \mathrm{kcal} / \mathrm{mol})$. The compound was found to be stabilized within the active site through an extensive chain of favorable van der Waals interactions observed with Cys387(-3.463), Asn385(-1.651), Phe369(-1.374), Lys367(-2.704), Phe366(-1.268), Val365(-4.669), Leu363(-2.049), Gln336(-1.763), Gln334(-1.44), $\operatorname{Arg} 325(-10.823), \operatorname{Asn} 324(-1.039)$, Phe320(-2.084), Leu317(-2.551), Trp230(-1.012), His 132(-3.631), Ile131(-1.393), Gly117(-1.577), Pro116(-2.175), and Tyr60(-1.545). Analysis of polar contacts such as electrostatic and pi-pi stacking interactions displayed that $7 \mathbf{a}$ formed multiple closed interactions with Lys418(-2.185), Tyr415(-1.565), Arg413(-9.938), Lys367(-1.418), Lys134(-1.73), Arg119(-1.872), Gly117(-1.463), Pro116(-1.49) and , Arg58(-1.037) residues of DprE1. Strong binding of 7a with active site of DprE1 is also contributed by its position in the pi-interaction in space of His 132 and through significant hydrogen bonding interactions with Lys418 and Gly117. Although all benzo[b]thiophene-2carboxylic acid derivatives were observed to show similar binding patterns, the presence of relatively stronger noncovalent interactions in terms of van der Waals, electrostatic and pi-pi interactions and the higher number of intermolecular hydrogen bonds augments the stronger binding of the compound $7 \mathbf{a}$ to the active site of DprE1.

In summary, our work demonstrates benzo[ $[b]$ thiophenes as a new family of inhibitors with potent antimycobacterial properties. The most promising compounds in the present 
series, $8 \mathrm{c}$ and $\mathbf{8 g}$, showed excellent activity and inhibited the growth of both active and dormant $M$. bovis BCG with MIC $_{90}$ of $0.56-0.62 \mu \mathrm{g} / \mathrm{mL}$ range. Molecular docking studies of these benzo[b]thiophene-2-carboxylic acid derivatives have shown a high binding affinity toward the active site of DprE1 enzyme, which provides a strong platform for development of the lead molecules for this series forming potent antitubercular agents. Overall, our ex vivo infection model indicates that there is significant potential for $\mathbf{7 b}$ for the treatment of tuberculosis. Meanwhile, diverse structural modifications are currently being investigated through iterative synthesis in conjugation with computer modeling, and the results will be given in due course.

\section{ASSOCIATED CONTENT}

\section{S Supporting Information}

The Supporting Information is available free of charge on the ACS Publications website at DOI: 10.1021/acsmedchemlett.6b00077.

Experimental procedures for the synthesis of $4,7 \mathbf{a}-\mathbf{g}$, $8 \mathrm{a}-\mathrm{g}, 9 \mathrm{a}-\mathrm{g}$, and $11 \mathrm{a}-\mathrm{i}$, representative ${ }^{1} \mathrm{H} \mathrm{NMR},{ }^{13} \mathrm{C}$ NMR, FT-IR, and HRMS spectra for final compounds, and details of in vitro and ex vivo assay (PDF)

\section{AUTHOR INFORMATION}

\section{Corresponding Author}

*Tel: (+91) 240 2403311. Fax: (+91) 240 2400491. E-mail: chgill16@gmail.com.

\section{Author Contributions}

P.S.M. performed the chemical syntheses. V.M.K. performed the molecular docking study. L.U.N. and D.S. performed in vitro and ex vivo biological screenings. C.H.G. participated in the design and execution of this study.

\section{Notes}

The authors declare no competing financial interest.

\section{ACKNOWLEDGMENTS}

P.S.M. thanks UGC, and M.D.N. thanks CSIR for a fellowship. We are also grateful to the National Chemical Laboratory, Pune, for providing antitubercular activity.

\section{REFERENCES}

(1) Johnson, R.; Streicher, E. M.; Louw, G. E.; Warren, R. M.; Helden, P. D.; Victor, T. C. Drug Resistance in Mycobacterium tuberculosis. Curr. Issues Mol. Biol. 2009, 8, 97-112.

(2) Anti-Tuberculosis Drug Resistance in the World; World Health Organization: Geneva, Switzerland, 1998.

(3) World Health Organization, Global Tuberculosis Report; WHO, 2003.

(4) Rai, D.; Johar, M.; Srivastav, N. C.; Manning, T.; Agrawal, B.; Kunimoto, D. Y.; Kumar, R. Inhibition of Mycobacterium tuberculosis, Mycobacterium Bovis, and Mycobacterium avium by Novel Dideoxy Nucleosides. J. Med. Chem. 2007, 50, 4766-4774.

(5) Colditz, G. A.; Brewer, T. F.; Berkey, C. S.; Wilson, M. E.; Burdick, E.; Fineberg, H. V.; Mosteller, F. Efficacy of BCG vaccine in the prevention of tuberculosis. Meta-analysis of the published literature. JAMA, J. Am. Med. Assoc. 1994, 271, 698-702.

(6) Pore, V. S.; Divse, J. M.; Charolkar, C. R.; Nawale, L. U.; Khedkar, V. M.; Sarkar, D. Design and synthesis of $11 \alpha$-substituted bile acid derivatives as potential antituberculosis agents. Bioorg. Med. Chem. Lett. 2015, 25, 4185-4190.

(7) Kulkarni, R. R.; Shurpali, K.; Puranik, V. G.; Sarkar, D.; Joshi, S. P. Antimycobacterial Labdane Diterpenes from Leucas stelligera. J. Nat. Prod. 2013, 76, 1836-1841.
(8) Akhtar, S.; Khan, A.; Sohaskey, C. D.; Jagannath, C.; Sarkar, D. Nitrite Reductase NirBD is induced and plays an important role during in vitro dormancy of Mycobacterium tuberculosis. J. of Bact. 2013, 195, 4592-4599.

(9) Khan, A.; Sarkar, D. A simple whole cell based high throughput screening protocol using Mycobacterium Bovis BCG for inhibitors against dormant and active tubercle bacilli. J. Microbiol. Methods 2008, $73,62-68$.

(10) Jadhav, G. R.; Shaikh, M. U.; Kale, R. P.; Shiradkar, M. R.; Gill, C. H. SAR study of clubbed $[1,2,4]$-triazolyl with fluorobenzimidazoles as antimicrobial and antituberculosis agents. Eur. J. Med. Chem. 2009, 44, 2930-2935.

(11) Gill, C.; Jadhav, G.; Shaikh, M.; Kale, R.; Ghawalkar, A.; Nagargoje, D.; Shiradkar, M. Clubbed $[1,2,3]$ triazoles by fluorine benzimidazole: a novel approach to $\mathrm{H} 37 \mathrm{Rv}$ inhibitors as a potential treatment for tuberculosis. Bioorg. Med. Chem. Lett. 2008, 18, 62446247.

(12) Singh, U.; Akhtar, S.; Mishra, A.; Sarkar, D. A novel screening method based on menadione mediated rapid reduction of tetrazolium salt for testing of anti-mycobacterial agents. J. Microbiol. Methods 2011, 84, 202-207.

(13) Wallace, R. J.; Nash, D. R.; Steele, L. C.; Steingrube, V. Susceptibility testing of slowly growing mycobacteria by a microdilution MIC method with $7 \mathrm{H} 9$ broth. J. Clin. Microbiol. 1986, 24, 976-981.

(14) Ashtekar, D. R.; Costa-Perira, R.; Nagrajan, K.; Vishvanathan, N.; Bhatt, A. D.; Rittel, W. In vitro and in vivo activities of the nitroimidazole CGI 17341 against Mycobacterium tuberculosis. Antimicrob. Agents Chemother. 1993, 37, 183-186.

(15) Mosmann, T. Rapid colorimetric assay for cellular growth and survival: application to proliferation and cytotoxicity assays. J. Immunol. Methods 1983, 65, 55-63.

(16) Ciapetti, G.; Cenni, E.; Pratelli, L.; Pizzoferrato, A. In vitro evaluation of cell/biomaterial interaction by MTT assay. Biomaterials 1993, 14, 359-364.

(17) Sreekanth, D.; Syed, A.; Sarkar, S.; Sarkar, D.; Santhakumari, B.; Ahmad, A.; Khan, M. I. J. Microbiol. Biotechnol. 2009, 19, 1342-1347.

(18) Orme, I.; Secrist, J.; Anathan, S.; Kwong, C.; Maddry, J.; Reynolds, R. Search for New Drugs for Treatment of Tuberculosis. Antimicrob. Agents Chemother. 2001, 7, 1943-1946.

(19) Luo, X.; Pires, D.; Ainsa, J. A.; Gracia, B.; Duarte, N.; Mulhovo, S.; Anes, E.; Ferreira, M. J. Zanthoxylum capense constituents with antimycobacterial activity against Mycobacterium tuberculosis in vitro and ex vivo within human macrophages. J. Ethnopharmacol. 2013, 146, $417-422$.

(20) Hartkoorn, R.; Chandler, B.; Owen, A.; Ward, S. A.; Squire, S.; Back, D. J.; Khoo, S. H. Differential drug susceptibility of intracellular and extracellular tuberculosis, and the impact of P-glycoprotein. Tuberculosis 2007, 87, 248-255.

(21) Wayne, L. G.; Hayes, L. G. An in vitro model for sequential study of shiftdown of Mycobacterium tuberculosis through two stages of nonreplicating persistence. Infect. Immun. 1996, 64, 2062-2069.

(22) Kuo, H. P.; Ho, T. C.; Wang, C. H.; Yu, C. T.; Lin, H. C. Increased production of hydrogen peroxide and expression of $\mathrm{CD} 1 \mathrm{lb} /$ CD18 on alveolar macrophages in patients with active pulmonary tuberculosis. Tuber. Lung. Dis. 1996, 77, 468-475.

(23) Grimble, R. F. Malnutrition and the immune response. 2. Impact of nutrients on cytokine biology in infection. Trans. $R$. Soc. Trop. Med. Hyg. 1994, 88, 615-619.

(24) Favier, A.; Sappey, C.; Laclerc, P.; Faure, P.; Micoud, M. J. Antioxidant status and lipid peroxidation in patients infected with HIV. Chem.-Biol. Interact. 1994, 91, 165-180.

(25) Yu, L. Free Radical Scavenging Properties of Conjugated Linoleic Acids. J. Agric. Food Chem. 2001, 49, 3452-3456.

(26) Kilclgil, A. H.; Coban, T.; Tuncbilek, M.; Can-Eke, B.; Dundar, O. B.; Ertan, R.; Iscan, M. Antioxidant properties of flavone-6(4')carboxaldehyde oxime ether derivatives. Arch. Pharmacal Res. 2004, 27, 610-614. 
(27) Riccardi, G.; Pasca, M. R.; Chiarelli, L. R.; Manina, G.; Mattevi, A.; Binda, C. The DprE1 enzyme, one of the most vulnerable targets of Mycobacterium tuberculosis. Appl. Microbiol. Biotechnol. 2013, 97, $8841-8848$.

(28) Wolucka, B. A. Biosynthesis of D-arabinose in mycobacteria -a novel bacterial pathway with implications for antimycobacterial therapy. FEBS J. 2008, 275, 2691-2711.

(29) Shirude, P. S.; Shandil, R.; Sadler, C.; Naik, M.; Hosagrahara, V.; Hameed, S.; Shinde, V.; Bathula, C.; Humnabadkar, V.; Kumar, N.; Reddy, J.; Panduga, V.; Sharma, S.; Ambady, A.; Hegde, N.; Whiteaker, J.; McLaughlin, R. E.; Gardner, H.; Madhavapeddi, P.; Ramachandran, V.; Kaur, P.; Narayan, A.; Guptha, S.; Awasthy, D.; Narayan, C.; Mahadevaswamy, J.; Vishwas, K. G.; Ahuja, V.; Srivastava, A.; Prabhakar, K. R.; Bharath, S.; Kale, R.; Ramaiah, M.; Choudhury, N. R.; Sambandamurthy, V. K.; Solapure, S.; Iyer, P. S.; Narayanan, S.; Chatterji, M. Azaindoles: Noncovalent DprE1 Inhibitors from Scaffold Morphing Efforts, Kill Mycobacterium tuberculosis and Are Efficacious in Vivo. J. Med. Chem. 2013, 56, 9701-9708.

(30) Brecik, M.; Centárová, I.; Mukherjee, R.; Kolly, G. S.; Huszár, S.; Bobovská, A.; Kilacsková, E.; Mokošová, V.; Svetlíková, Z.; Šarkan, M.; Neres, J.; Korduláková, J.; Cole, S. T.; Mikušová, K. DprE1 Is a Vulnerable Tuberculosis Drug Target Due to Its Cell Wall Localization. ACS Chem. Biol. 2015, 10, 1631-1636.

(31) Neres, J.; Hartkoorn, R. C.; Chiarelli, L. R.; Gadupudi, R.; Pasca, M. R.; Mori, G.; Venturelli, A.; Savina, S.; Makarov, V.; Kolly, G. S.; Molteni, E.; Binda, C.; Dhar, N.; Ferrari, S.; Brodin, P.; Delorme, V.; Landry, V.; Ribeiro, A. L.; Farina, D.; Saxena, P.; Pojer, F.; Carta, A.; Luciani, R.; Porta, A.; Zanoni, G.; Rossi, E.; Costi, M. P.; Riccardi, G.; Cole, S. T. 2-Carboxyquinoxalines Kill Mycobacterium tuberculosis through Noncovalent Inhibition of DprE1. ACS Chem. Biol. 2015, 10, $705-714$.

(32) Chikhale, R.; Menghani, S.; Babu, R.; Bansode, R.; Bhargavi, G.; Karodia, N.; Rajasekharan, M. V.; Paradkar, A.; Khedekar, P. Development of selective DprE1 inhibitors: Design, synthesis, crystal structure and antitubercular activity of benzothiazolylpyrimidine-5carboxamidesOriginal Research Article. Eur. J. Med. Chem. 2015, 96, $30-46$.

(33) Friesner, R. A.; Banks, J. L.; Murphy, R. B.; Halgren, T. A.; Klicic, J. J.; Mainz, D. T.; Repasky, M. P.; Knoll, E. H.; Shelley, M.; Perry, J. K.; Shaw, D. E.; Francis, P.; Shenkin, P. S. Glide: A New Approach for Rapid, Accurate Docking and Scoring. 1. Method and Assessment of Docking Accuracy. J. Med. Chem. 2004, 47, 1739-1749.

(34) Friesner, R. A.; Murphy, R. B.; Repasky, M. P.; Frye, L. L.; Greenwood, J. R.; Halgren, T. A.; Sanschagrin, P. C.; Mainz, D. T. Extra Precision Glide: Docking and Scoring Incorporating a Model of Hydrophobic Enclosure for Protein-Ligand Complexes. J. Med. Chem. 2006, 49, 6177-6196 and references cited therein.. 